Dejan DONEV

UDC:174:001.891

Original research paper

\title{
THE IMPERATIVE RESPONSIBILITY: THE RETURN OF ETHICS IN SCIENCE
}

\section{Abstract:}

At the height of self-satisfaction from the technical-technological progress, in the 20 th century, it was forgotten that science and philosophy begin with wonder, astonishment. Wonder, of course, has a dimension of ignorance. Ignorance, at least according to Aristotle, is the ignorance of the reason which people are trying to find out. This is how science is born, scientific processes are started, which are similar during the solution of geometric, astronomical, or problems of modern genetics.

But the rapid development of technology in the 20th century also left the man with a whole new moral situation of spreading scientific and technological achievements, a process that is an unstoppable anthropological phenomenon because it is an ontological determinant of modern man. Society, the community, really has a difficult task to balance between scientific freedom of expression and the responsibility to uphold social norms and societal values.

The existing mostly heteronymous prohibitions, although necessary, are not sufficient unless the scientists themselves develop an awareness that the general humanistic moral principles and the principles of scientific critique, especially the principle of responsibility, should be followed.

Keywords: ethics, responsibility, science, research, scientist

\section{Introduction}

Let's currently analyze the quantum and applied value of scientific knowledge available to today's man. It seems that the statement "knowledge is power" (Scientia potential est) is correct because science is no longer just a modest feat that is the product of symbiosis between man's natural curiosity and his fear of nature, but also a means by which he would master nature and remove the shackles in which he was chained, becoming a free man, deprived of all torment and suffering. At the same time, this statement is, to a large extent, absolutely ambiguous - the two faces of the Roman god Janus: the time in which we live, despite that large amount of knowledge and increased applicative value, is still characterized by an enormous number of unresolved issues that as accumulated burdens are dragged on for decades and decades, and are the result of the indolent attitude and behavior of man in various spheres of life. 
"The world we live in today is neither an ordinary environmental crisis nor a society at risk, but it is a technologically advanced civilization whose innovations could destroy much more than we are able to predict at all and bear responsibility for the future generations. If we look at things this way, then it really is a civilization that is full of dangers and a society that threatens its future, and the rules of this civilization are constantly creating cumulative long-term consequences that call into question the further existence of the real human life on Earth, because with its constant endangerment or even endangerment of the ecological and socio-cultural foundations of life, at the same time the conditions of freedom and taking responsibility of future generations are even more endangered ..." (Bohler \& Gronke, 2003: 1077).

The multitude of problems related to science, especially research, and mostly the application of scientific research ${ }^{1}$, are dominated by those who have shown that even the best intentions do not have a good result and consequence (Arnaldi \& Bianch, 2016: 1), which reciprocally means the need to expand and change the field of morality. This is even more because the current position of science in modern society has led to a state in which knowledge can be both a cure and a disease, and according to some authors, "created an artificial world that carries a greater burden than nature" (Mitcham \& Briggle, 2005: 1061). It ultimately resulted in the actualization of the discourse on the need to find a new approach, appropriate mechanisms for social and moral control of science, both in the scientific research process and in terms of knowledge gained in that process. Namely, there is more and more insistence in scientific research to re-introduce ethics, normative ethics, but not only as a regulator and "final judge" of what is done and applied but also as an incentive to develop ethical awareness and conscience to no dire consequences occur due to the new commercialization of science (Krimsky, 1991). That is why the efforts for "humanization" of science and technology are growing, instead of the apparent tendencies for ideologizing technology and the introduction of technocracy.

The efforts to bring the idea of humanization of science to life through the idea of a moral scientist seeking the truth are becoming more evident, without being driven by the need to fabricate, falsify, misinterpret data, hide the acquired knowledge and distance oneself from the consequences that with his research he produces them in the broader social community. The scientist is the "human dimension" of science, a bridge between nature and society. In this sense is the idea that any action plan to "curb" science is essentially redefining the professional role of the scientist by emphasizing the responsibility that is immanent to his position as an individual with special abilities, but also by reaffirming the basic epistemological and methodological principles that he should

\footnotetext{
${ }^{1}$ On what indicates and Edward Diener \& Rick Crandall, Ethics in Social and Behavioral Research, University of Chicago Press, Chicago, 1978, as well as Lucinda Peach, "An Introduction to Ethical Theory", in Robin Levin Penslar (ed.), Research Ethics: Cases and Materials, Indiana University Press, Bloomington, 1995, p.p. 13-26.
} 
adhere to in conducting scientific research, which is threatened by the permanent privatization of science and increased academic competition that leads to quantity, not quality.

Of course, this does not mean ignoring the fact that science as a form of power does not depend solely on the scientist's character. Still, it is necessary to consider other actors in the overall scientific process, such as academic institutions, research centers, publishers. Scientific publications, political factors, and public opinion have an appropriate position in the image of science today.

\section{The need for a new "responsible" approach to scientific research}

This situation has arisen as a result of the "loosening of the moral reins" due to the social changes that have taken place, and also due to a whole series of causes and events, as well as the growing social fragmentation, and eventually due to it the declining intensity of social life and public engagement, due to which, in a general sense, the change of the cultural process and the pattern that emerged and developed thanks to the Postmodern is mainly blamed. As Zygmunt Bauman points out, there is a "distrust of metanarratives" (Bauman, 1993), which results in the rejection of the possibility of universal, ethically based standardization. In the light of postmodern relativism, a complete thesis is understood as something "intended for the landfill of history" (Bauman, 1993: 2). The final consequence is the beginning of the new meaning of the paradox contained in Rousseau's statement that man is born free and is chained everywhere, except that the previous "ruthless master - nature" has already been pushed out of precisely the tool he was supposed to overcome - science or technology as the "applied science" that was to be the final product of Bacon's idea, the new ultimate truth. Now science has emerged in the role of the new master!

But because the Postmodern has committed the most remarkable "sin" in each of the spheres of human existence and action, destroying its individuality and uniqueness by erasing its authenticity and introducing relativism to the big door - the current demand for a return to ethics and ethical, and in research, it expresses man's concern for his present, but more importantly, for his future, in an attempt to rediscover his essence, meaning, and purpose of existence. In the part of the research, this shows that scientists, trying to think ethically about the causes and consequences of their research, at the same time try through ethics to find the meaning of the existence and justification of the results they have reached. That is why it is no coincidence that the physicist Carl Friedrich von Weizsäcker once bitterly insisted that scientists' degree of moral maturity should be measured by productive responsibility for the consequences of the knowledge they practically assume (Weizsäcker, 1980).

This stems from the knowledge of the high standards that ethics offers, which are reflected as a higher quality in/of research, which significantly increases the social impact of research: by promoting research integrity, they align 
research with societal needs and expectations. It is, therefore, necessary to find and re-accept the morally justified reasons why research is required to undergo ethical evaluation following the ethical evaluation system because what is essential is to identify the potential benefits and risks that arise as a result of the research, and whose main feature is independence (Bortolotti \& Heinrichs, 2007: 157-179).

The idea is first of all to "achieve four things", and that is to "show the practical value of serious and systematic thinking about what kind is and what is the ethical behavior in research", further "to determine how and why we are in a situation of incomprehensible phenomena from the existing systems of regulation", but also to "clear the field and emphasize those acts that led to antagonism between researchers and regulators", as well as to "encourage both parties to jointly devise solutions to ethical and regulatory issues" (Israel \& Hay, 2006: 20). Hence, it is essential to continue to believe that any research is not intrinsically ethically questionable at its core. Despite the problems that arise during its implementation, there are several reasons why it should be supported and viewed as a worthwhile activity.

Namely:

- "research brings a better quality of life and increases well-being;

- more lives can be saved;

- knowledge can be good for itself" (European Commission, 2010: 14).

These reasons now justify two different types of responsibility in conducting research. "The first is an ethical argument - extraintrific value - which is built on the idea of knowledge arising from good science" (European Commission, 2010: 14) and according to which research is valuable, valid for the benefit of the knowledge that is implemented in society. "The second argument refers to the idea of knowledge as intrinsically valuable, i.e. what is inherently valuable, regardless of any further benefit" (European Commission, 2010: 15) that may arise from its application. ${ }^{2}$

According to many contemporary authors, the shortcomings of such considerations become even more apparent by abandoning the strict distinction between theoretical and applied science and shifting the focus from purely theoretical research to research driven by the immediate need to solve a particular

\footnotetext{
${ }^{2}$ At the same time, these two different fundamental types of responsibility in conducting research in the natural and social sciences and their research methodology, have different weight and importance because in the social sciences the question of choice and moral responsibility weighs, because their methods do not have that degree of value neutrality, in fact the ideal of objectivity, as in the natural sciences. Here it is already significantly more difficult to make a discrepancy between the researcher and his subject of research, which preserves objectivity, which necessarily raises the question of freedom in the activities of human life as a key assumption of the meaning of his life and values. It would be said that in the social sciences the problem of ethical evaluation of research is more complicated due to the issue of articulation of freedom and its limits because in such research it is impossible to avoid using the human individual and parts of society as research material.
} 
problem. This indicates that science necessarily "absorbs" in itself external or contextual values (which are not of an epistemological nature) expressed as a common good and which are most subtly expressed in the choice of the subject of scientific interest. When this is followed by the possibility of some scientific knowledge or the path (technique) used to reach it to lead to negative consequences, it is necessary to see science in a broader social context. It becomes essential to redefine ethics in science because the principle "do not do what you do not want them to do to you" is no longer enough.

In this context, Hans Jonas is one of the first to recognize the "diffusion" between theory and practice and create a new "ethics for the technological age" (Hansen, 2006: 83) that no longer focuses on the individual. Still, he is based on the moral responsibility of humankind for the future - total responsibility to preserve life on Earth, projected as a fusion of individual and social responsibility through a modification of Kant's categorical imperative: "Act so that the consequences of your activity correspond to the continuity of human life" (Jonas, 1984: 11). Starting from the view that "the rape of nature and the cultivation of man go hand in hand" (Jonas, 1984: 4), Jonas positions responsibility at the center of ethics and bases it on the fact that humanity is moving towards the abyss and can no longer control its power over nature that will lead to its destruction, especially in a situation where human activities related to technological processes go beyond the temporal and spatial framework in which it is possible to anticipate their consequences.

In other words, research can, and now must be methodologically ethical, not just scientific (Dawson \& Yentis, 2007: 165-176), indicating the need to find new appropriate approaches/models of action. These are unique and significantly different circumstances of social life whose implications are a challenge for modern society and justifiably require us to carefully consider the (bio)ethical responsibility of man as an individual and as a social being.

\section{For ethics of responsibility in modern times}

A step further in the previous claim is that a way out of the crisis is possible, but only as a reminder of science sources, and in those processes, philosophy plays an important role. Of particular importance is the legacy of the ancient philosophical tradition. "Science" in the ancient definition (following the example of Aristotle) is living in truth, as a practical consequence of observing the essence or truth of things: "All men by their very nature aspire to truth" (Aristotel, 1960: 980 a 1).

Thus man needs a new, never-before-added dimension of responsibility. Such responsibility as an ethical category is significantly different from previous anthropocentric approaches, and it is a consequence of a whole series of new life circumstances and conditions of survival. It is ethics in which the center of responsibility is positioned and supported by the knowledge that humanity moves towards the abyss. It is no longer possible to control its power over na- 
ture (which leads to its downfall). Therefore, the question of the responsibility of scientists and philosophers is crucial, as an essential question for scientific action, and not only as a side issue according to a cliché that can but does not have to be related to what is happening in the field of science and philosophy.

This question, moreover, must be what starts in every scientific and philosophical act, with full awareness of the possible abuses and negative consequences that can follow from almost any result: "Today scientists are constantly looking for funding for its research, which usually leads them to focus directly on research aimed at solving a particular problem of everyday human life, at the expense of "pure" science, which is the universal basis for any further research in a particular field" (Saenko et al., 2019: 336). Examples of this lack of complete awareness of responsibility can be found daily in the efforts to inject disproportionately large funds into scientific programs and projects that have practical application, i.e. in the efforts to give significantly fewer funds in the so-called "pure science" (Seumas, 2013: 205), i.e. "in fundamental research that does not bring immediate benefit, but enables the development of science as such" (Bird, 2014: 170).

Accordingly, the reasons for today's crisis and concern about the consequences of these processes lie in the crucial but not sufficiently pronounced distinction between discovery and the application of science: "What shall we do with the knowledge that science discovers? That is not the job of science itself! Science has nothing to do with the question of good and evil, with the satisfaction of human desires ... Hence, it is our responsibility in the name of science to decide what is worth doing, before we use science to do it" (MacMurray, 1968: 36).

At the same time, modern scientific bureaucracies and modern technical advances and solutions have recently made significant progress in all spheres of natural, private, and public life - making sense on their own, while at the same time taking away meaning from the increasingly difficult individual to understand the meaning of one's participation in the mentioned event. "The disease of the modern age lies in the inability of the individual to understand his meaning and the lack of interest to be directed to the current state of crisis" (Gretić, 1998: 145).

In such circumstances, so far, all other possible feedback mechanisms of human action on nature and the world around us have been neglected. The consequences of such a relationship today are anything but negligible. In short, what we might call Bacon's program of mastering nature with the help of science and technology threatens a general catastrophe the size of its success. At the top of the triumph is revealed its lack, contradiction, and loss of self-control. Finally, today's man is not only incapable of protecting nature as a whole, but he is also incapable of protecting himself: Everyone is the cause but also the consequence of his disappearance!

Following the thoughts of Hans Jonas, it could be said that this situation is an absurdity of modern times, a kind of "paradox of power" in which power 
over nature simultaneously leads to absolute human submission. The way out of this dialectic of power is possible only by introducing the next degree of power. It seeks "power over power" to regain control of its own power over nature and break its tyranny over man (Jonas, 1990: 197-199). That is why Jonas pleads for a voluntary "self-censorship of science in the name of responsibility which must not allow our greatly increased power to overcome us or those who come after us" (Jonas, 1985: 80). Thus, everything previously prompted the establishment of ethics, "ethics for the technological age" (Hansen, 2006: 83) which is capable of raising the question of the morality of scientists, their responsibility for scientific discoveries with harmful technological consequences, and the moral guilt of technological scientists for the implications of the technical application of science, which have already caused a global threat to the planet and man. Ethics that "no longer has the individual at the center, but is based on humanity's moral responsibility for the future - an unlimited responsibility to preserve life on Earth, projected as a fusion of individual and social responsibility" (Jonas, 1984: 11).

Even more, Jonas, aware of the dangers of progressively disrupting the global components of human survival and life on the planet, developed an ethics of responsibility that is divided into three levels: individual, professional, and macro-ethical level, a "network of responsibilities" (Brall et al., 2017: 2735) constituted from different relations of the moral responsibilities of scientists with other actors in the scientific process, and which relations are frightening with the growing commercialization of science. Well, trying, he affirmed, like Kant, the new ethical categorical imperative: "Act so that the consequences of your actions are not destructive to the future possibility of such a life" (Jonas, 1990: 28). Max Scheller joined the same, criticizing the positive sciences from the point of view of the ethics of values, saying that the sciences, in their quasi-neutrality versus the value system, wisely hide the "scientific mind", which in scientific procedure and application removes any moral and other valuation for the will of a single "value above values "- the value of power!

So, although from the very development of modern science, and even later, the belief of scientists prevailed that science as such has nothing to do with ethics: "science does not make ethical or moral judgments ... Science provides society with facts that are relevant to carry of value reasoning, but it itself does not engage in moral decision-making" (Rollin, 2006: 17-18). Even more, that it has nothing to do with any teleological view of the world and that scientific work with the world and life must take place without political or any other interferences in complete freedom (Ehni, 2008: 149).

However, especially today, the belief that science is not value-neutral is increasingly on the scene. The concept of neutrality of science that serves scientists by hiding under the guise of objectivity to avoid responsibility for the negative implications of their scientific activity does not apply. Science is increasingly closely linked to political power, i.e. that it is a special kind of power policy because it is related to the dominant governing centers of power through 
scientific institutions. ${ }^{3}$ Therefore, for scientists' power, they should take moral responsibility in their scientific work and engagement. The freedom of scientific research must be, like any other freedom, morally responsible freedom. Responsible conduct of scientific research is required in which every scientist should "follow pre-defined ethical standards and values in conducting and publishing research" (Resnik \& Elliott, 2016: 31-46). They are the ones who are most competent to assess the risks posed by science and technology, and it is more than confident that they are the ones who know best the directions and scales on which scientific knowledge can be extended. Hence, every scientist has to walk the path of research following established ethical principles and to be ready to bear the burden of the results of his research, to show the moral will to reciprocate to humanity for the "honor" bestowed upon him and the resources which are invested in his education.

In conclusion, regardless of such primarily theoretical explanations, it is generally accepted that the scientist as a bearer of a unique role in society and "master" of particular, specific knowledge has a duty not only to increase general well-being but also to prevent adverse effects that his activity can have them both on the individual and society as a whole. Namely, given his abilities, the scientist is the one who can most accurately (and in any case better than the average person and politician) evaluate the results of his research to anticipate the direct and indirect consequences to which the acquired knowledge can lead, as well as to analyze the connection between his research and his product and to place it in the broader social context. It is simply necessary for the scientist to respect the basic rule that science should maximize the common good while minimizing the possibilities of destruction.

In this situation, and especially when engaging in research that results in dual-application knowledge, the scientist somehow balances "intentional good" and "predictable evil" 4 . Of course, there is always the possibility in the long run of completely unexpected practical implications of the acquired knowledge that would bring uncertainty to society. There is a risk of a "Promethean Gap", a term used by Guenter Anders to describe "asymmetry between readiness for action and the ability to predict the consequences of action" (Arnaldi \& Bianch, 2016: 7), but this does not diminish the significance of this somewhat "prophetic" function of the scientist.

\footnotetext{
${ }^{3}$ For modern science as a process, not as a happening, for the fact that science is creative, not groundbreaking, and as such should be in alliance with democratic change and transformation, not with the politics of power, it is instructive to look Isabelle Stengers, The Invention of modern Science, University of Minnesota Press, 2000.

${ }^{4}$ Hans-Jorg Ehni's thoughts on the indirect causal responsibility of the scientist for the negative use of knowledge that is a product of his scientific activity, are interesting . More in Hans Jorg Ehni, „Dual use and the ethical responsibility of scientists“, Archivum Immunologiae et Therapiae Experimentalis, 56 (2008): 147-152.
} 


\section{Prologue}

At the height of self-satisfaction from the technical-technological progress in the 20th century, it seems that we forget that science and philosophy begin with wonder, astonishment (Aristotel, 1988: b 11-21) ${ }^{5}$. Wonder, of course, has a dimension of ignorance. Ignorance, at least according to Aristotle, is ignorance of the reason people are trying to find out. This is how science is born. Scientific processes begin, which are similar in solving geometric, astronomical, or problems of modern genetics.

However, the rapid development of technology in the 20th century also left man with a completely new moral situation of spreading scientific and technological achievements, an unstoppable anthropological phenomenon because it is an ontological determinant of what modern man performs. Society, the community, really has difficulty balancing scientific freedom of expression and the responsibility to uphold social norms and values. "Scientific freedom ... is an acquired right, universally recognized by society and necessary for the advancement of knowledge from which society can benefit". But "scientific freedom and responsibility are essentially inseparable" (AAAS Committee on Scientific Freedom and Responsibility, 1975: 5). Thus, the new situation in which modern man must take responsibility for acts that are not the result of the actions of an individual, but are a collective act, "an act of an anonymous subject", Husserl would say, becomes even more complicated. The same is explained by the conclusion that the greater complexity of human action strengthens the need for ethical reflection!

There is no doubt that the dramatic changes that have taken place in the world in the last few decades are the result of the development of science, but it should not be forgotten that this is not the primary goal of science. The vital motive for people to enter science was and undoubtedly still is. The search for truth means one knowledge for the sake of knowledge. In this combination of motives related to the truth and the search for it, as well as its practical pretensions, the essential ambivalence of science and scientific development can be detected. The modern world is currently undoubtedly marked by the weighting of this second element, the practical aspect of science, i.e. the efficiency of applying its results in people's everyday lives, so the care of both science and scientists are often focused on achieving better as soon as possible results. The utilitarian moment was certainly not an eternal feature of science and scientific development. The search for truth, wonder, and curiosity are enduring features of scientific activity, something without which science simply cannot. On the other hand, the practical side is something that is on the way to science, while

\footnotetext{
${ }^{5}$ Aristotle writes about astonishment, wonder, about what does move us to philosophize, not only in For Heaven 294 a 11 - 28, but also in other places. Plato writes on the same subject, in Theaet (115 d) and in Phileb (14 c-e), but in him the wonder is primarily focused on the idea (Parmenides 129 c), while in Aristotle it is the case with the sensory world.
} 
questions about the essence of man and his world are its permanent, constant preoccupation. These specific human issues play a significant role in every scientific act, research, and experiment.

The existing predominantly heteronomous prohibitions, although necessary, are not sufficient unless the scientists themselves develop an awareness that the general humanistic moral principles and the principles of scientific critique should be followed. Hence, the issue of social responsibility of scientists must be (bio)ethically codified, an issue which, due to its adequate internalization, must be an integral part of the education of scientists from the earliest days. It is essential that scientists and philosophers, in their cognitions and insights, which especially in the humanities often have the character of value beliefs, not go below the achieved civilization standards of ethical and moral culture and think about various topics attention and awareness of dilemmas, whom they can meet in their professional work. 


\section{LITERATURE}

AAAS Committee on Scietific Freedom and Responsibility (1975). Scientific Freedom and Responsibility. Washington DC.: American Association for the Advancement of Science.

Aristotel (1960). Metafizika. Beograd: Kultura.

Aristotel (1988). Metafizika. Zagreb: Liber.

Arnaldi, Simone \& Luca Bianch (2016). Responsibility in Science and Technology: Elements of a Social Theory, Futures of Technology, Science and Society. Wiesbaden: Springer Fachmedien.

Bauman, Zygmunt (1993). Postmodern Ethics. Oxford: Blackwell.

Bird, Stephanie (2014). "Socially Responsible Science is more than Good Science", Journal of Microbiology \& Biology Education,15.2, 2014: 169-172.

Bohler, Dietrich \& Horst Gronke (2003). "In dubio pro responsabilitate", Filozoska istraživanja, Vol. 23, No. 91.

Bortolotti, Lisa \& Bert Heinrichs (2007). “Delimiting the concept of research: An ethical perspective ", Theoretical Medicine and Bioethics 28, No.3, 2007: 157-179.

Brall, Caroline et al. (2017). "Research Ethics 2.0: New Perspectives on Norms, Values and Integrity in Genomic Research in Times of Even Scarcer Resources", Public Health Genomics, 20.1 (2017): 27-35.

Dawson, Angus \& Steve Yentis (2007). "Contesting the science/ethics distinction in the review of clinical research ", Journal of Medical Ethics 33, 2007: 165176.

Diener, Edward \& Rick Crandall (1978). Ethics in Social and Behavioral Research. Chicago: University of Chicago Press.

Ehni, Jorg, Hans (2008). "Dual use and the ethical responsibility of scientists", Archioum Immunologiae et Therapiae Experimentalis, 56 (2008): 147-152.

European Commission (2010). Europian Textbook on Ethics in Research. Luxembourg: Publications Office of the Europian Union.

Gretić, Goran (1998). „Husserlova ideja Europe kao umne zajednice“, Politička misao, (XXXV) 2.

Hansen, Borsen, Tom (2006). "Academic and Social Responsibility of Scientist", ISYP Journal on Science and World Affairs, 2.2. (2006): 71-92.

Israel, Mark \& Iain Hay (2006). Research Ethics for Social Scientists. London: SAGE.

Jonas, Hans (1990). Princip odgovornost. Sarajevo: Veselin Masleša..

Jonas, Hans (1985).Technik, Medizin, und Ethik - Zur Praxis des Princips Verantwortung. Frankfurt-M.

Jonas, Hans (1984). The imperative of Responsibility: In Search of an Ethics for the Technological Age. Chicago: University of Chicago.

Krimsky, Sheldon (1991). Biotechnics and Society - The rise of Industrial Genetics. New York: Praeger. 
Mitcham, Carl \& Adam Briggle (2005). "Humanization and dehumanization ", in Encyclopedia of Science, Technology and Ethics, Vol.1, Carl Mitcham (ed.). Thomson Gale: Farmington Hills.

Murray, Mac John (1968). Freedom in a Modern World. London: Faber and Faber.

Peach, Lucinda (1995). "An Introduction to Ethical Theory", in Research Ethics: Cases and Materials, Robin Levin Penslar (ed.). Bloomington: Indiana University Press.

Resnik, David \& Kevin Elliott (2016). "The Ethical Changes of Socially Responsible Science", Accountability in Research, 23:1 (2016): 31-46.

Rollin, Bernard (2006). Science and Ethics. New York: Cambridge University Press.

Saenko, Natalya et al. (2019). "The Social Responsibility of a Scientist: Philosophical Aspect of Contemporary Discussions", Journal of Social Studies Educational Research, 10.3 (2019): 332-345.

Seumas, Miller (2013). "Moral Responsibility, Collective Action Problems and the Dual-Use Dilemma in Science and Technology": On the Dual Uses of Science and Ethics: Principles, Practices and Prospects, Brian Rappert \& Michael Selgelid (eds.). Canberra: ANU Press.

Stengers, Isabelle (2000). The Invention of Modern Science. Minnesota: University of Minnesota Press.

Weizsäcker, Friedrich von, Carl (1980). The Unity of Nature. New York: Farrar Straus Giroux. 